\title{
SOFTWARE APPLICATION FOR SOLVING OF NON-STATIONARY TEMPERATURE FIELDS IN TWO-LAYER PLATE
}

\author{
CHARVATOVA, H[ana]; VASEK, V[ladimir]; DRGA, R[udolf] \& KRENEK, J[iri]
}

Abstract: In this paper we deal with computer modeling of nonstationary conduction of heat in two-layer solid plate by mathematic software Maple. For this purpose, we describe user interface and basic functions of a software application that we programmed in the Maple for automatic computing of temperature fields in the solid plate during mentioned thermal processes.

Key words: non-stationary conduction of heat, mathematical modeling, two-layer plate, Maple.

\section{INTRODUCTION}

Non-stationary conduction of heat in the solid material belongs to common phenomena that occur in all branches of industry during natural and synthetic materials thermal processing. These processes course can significantly influence both economical costs and quality of the final products (Janáčová et al., 2010), (Sýkorová et al., 2011).
For a suitable technological process proposal, it is necessary to know the operation course. The optimal process proposal can be determined by both experimentally (i.e. by using of the appropriate analytical method) and appropriate mathematical model solving.

In this contribution we will continue the paper (Janáčová et al., 2011), in which we formulated mathematic model of the mentioned process and verified its validity. In the following text we will deal with computer modeling of non-stationary conduction of heat in two-layer solid plate by mathematic software Maple. We will describe user interface and basic functions of a software application that we programmed for computing of temperature fields in the solid plate during mentioned thermal processes in the Maple user interface.

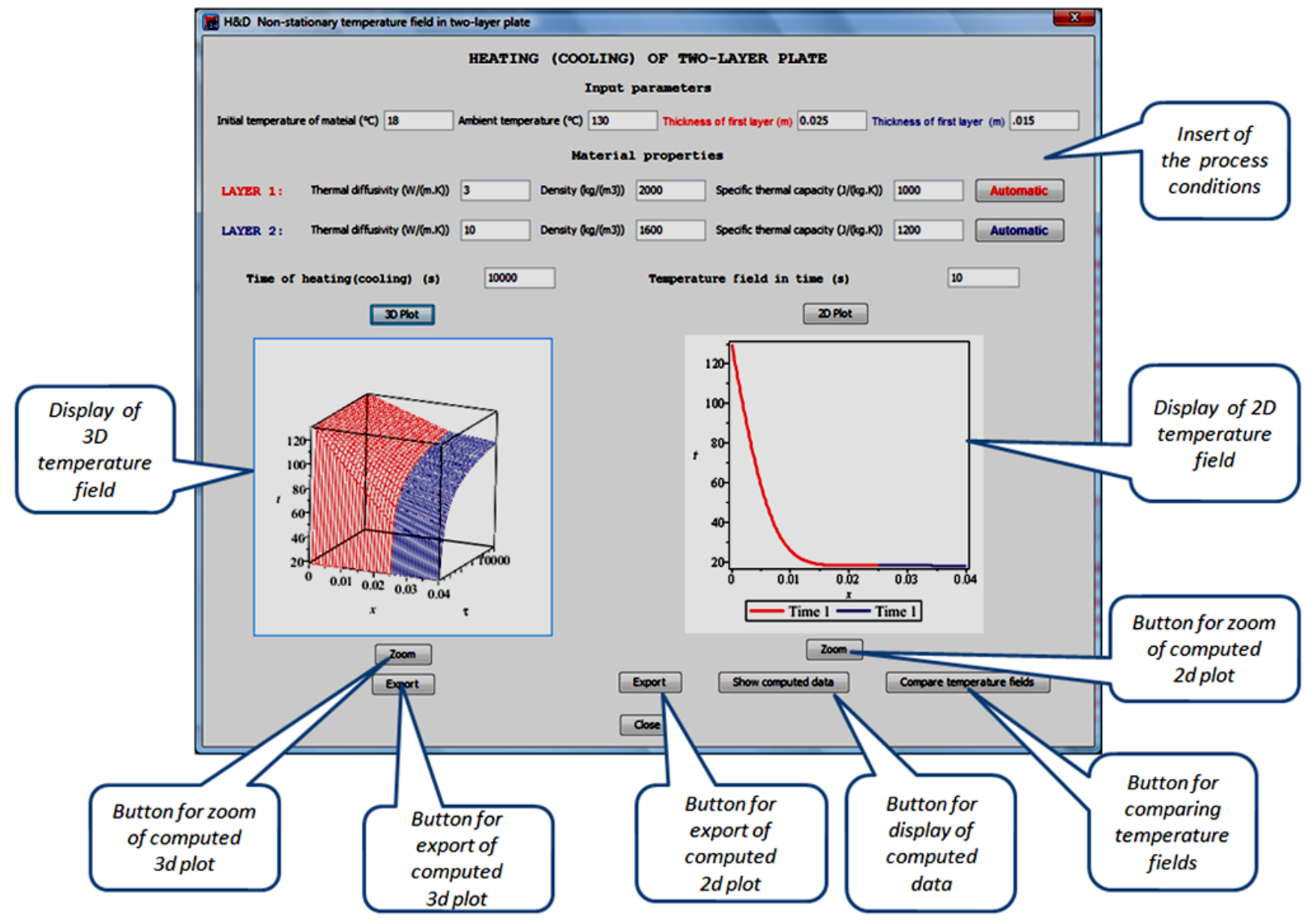

Fig. 1. User interface of the programmed software application for computing of temperature fields in two-layer solid plate 


\section{COMPUTER MODELING OF NON- STATIONARY TEMPERATURE FIELDS BY MAPLE}

Maple is a system for doing mathematic on a computer. It can combine symbolic manipulation, numerical mathematics, outstanding graphics, and a sophisticated programming language. Because of its versatility, Maple has established itself as the computer algebra system of choice for many computer users including scientists, engineers, students, etc. (Abell \& Braselton, 2005). For this occasion, Maple has many tools that can make easy and speed up comparatively difficult computing. Therefore we elected mathematic software Maple for study of non-stationary heating and cooling two-layer solid plate.

We programmed interactive application for modeling of the above described process of the heat action course in the Maple user interface. We also programmed the application in the Maplet form defined by source code

$>$ with(plots):

$>$ with(plottools):

use Maplets:-Elements

maplet := Maplet( onstartup = RunWindow( W1 ),

Window $[\mathrm{W} 1](\ldots)$,

Window $[\mathrm{W} 2](\ldots)$,

Window[W3](...),

);

end use:

Maplets:-Display( maplet );

The Maplet form enables us to insert required input parameters, automatic computing and display temperature fields in the plate. Based on analytical solution of the mathematic model formulated in paper (Janáčová et al., 2011), the computed data are display as both 3D graphics $t(x, \tau)$ and 2D graphics $t(x)$ in the required time of the process.

The fig. 1 depicts main window of the programmed software application. In this window user inserts required conditions of the process, as are initial temperature of the plate, temperature of the ambient fluid and material properties of the plate. After them, the temperature 3D and 2D temperature fields are automatic computed by click the relevant button.

Table with data computed for 2D temperature field can be also display in new window as depicts the fig. 2 .

\begin{tabular}{|c|c|c|c|c|c|c|c|c|}
\hline 橉 $\mathrm{H} \& \mathrm{D}$ & Message & & & & & & & $x$ \\
\hline \multicolumn{5}{|c|}{ LAYER 1: } & \multicolumn{4}{|c|}{ LAYER 2: } \\
\hline For $x=$ & 0 & $m, t=$ & 130. & ${ }^{\circ} \mathrm{C}$ & For $x=$ & $.265 \mathrm{e}-1$ & $\mathrm{~m}, \mathrm{t}=18.00019768$ & $\propto$ \\
\hline For $x=$ & $.25 \mathrm{e}-2$ & $\mathrm{~m}, \mathrm{t}=$ & 90.58460924 & $4{ }^{\circ} \mathrm{C}$ & For $x=$ & $.280 \mathrm{e}-1$ & $\mathrm{~m}, \mathrm{t}=18.00009510$ & ${ }^{\circ} \mathrm{C}$ \\
\hline For $x=$ & $.50 \mathrm{e}-2$ & $\mathrm{~m}, \mathrm{t}=$ & 58.46676801 & $1{ }^{\circ} \mathrm{C}$ & For $x=$ & $.295 \mathrm{e}-1$ & $\mathrm{~m}, \mathrm{t}=18.00004481$ & ${ }^{\circ} \mathrm{C}$ \\
\hline For $x=$ & $.75 \mathrm{e}-2$ & $m, t=$ & 37.14119427 & $7)^{\circ}$ & For $x=$ & $.310 \mathrm{e}-1$ & $\mathrm{~m}, \mathrm{t}=18.00002067$ & ${ }^{\circ} \mathrm{C}$ \\
\hline For $x=$ & $.100 \mathrm{e}-1$ & $m, t=$ & 25.60358536 & 5 & For $x=$ & $325 \mathrm{e}-1$ & $\mathrm{~m} t=18.00000934$ & $a^{\circ}$ \\
\hline For $x=$ & $.125 \mathrm{e}-1$ & $m, t=$ & 20.51763382 & $2{ }^{\circ}$ & & & & \\
\hline For $x=$ & $.150 \mathrm{e}^{-1}$ & $\mathrm{~m}, \mathrm{t}=$ & 18.69102872 & $2 \propto$ & For $x=$ & $.340 \mathrm{e}-1$ & $\mathrm{~m}, \mathrm{t}=18.00000413$ & ${ }^{\circ} \mathrm{C}$ \\
\hline For $x=$ & $.175 \mathrm{e}-1$ & $m, t=$ & 18.15658427 & 70 & For $x=$ & $.355 \mathrm{e}-1$ & $\mathrm{~m}, \mathrm{t}=18.00000179$ & ${ }^{\circ} \mathrm{C}$ \\
\hline For $x=$ & $.200 \mathrm{e}-1$ & $\mathrm{~m}, \mathrm{t}=$ & 18.02920035 & 5 & For $x=$ & $.370 \mathrm{e}-1$ & $\mathrm{~m}, \mathrm{t}=18.00000076$ & ${ }^{\circ} \mathrm{C}$ \\
\hline For $x=$ & $.225 \mathrm{e}-1$ & $m, t=$ & 18.00445518 & $\alpha^{\circ}$ & For $x=$ & $.385 \mathrm{e}-1$ & $\mathrm{~m}, \mathrm{t}=18.00000032$ & ${ }^{\circ} \mathrm{C}$ \\
\hline
\end{tabular}

Fig. 2. Window for display of the computed data

The temperature fields can be also compared for required time of the process (fig. 3). In the case of need, it is also possible to zoom or export the computed 2D and 3D temperature fields.

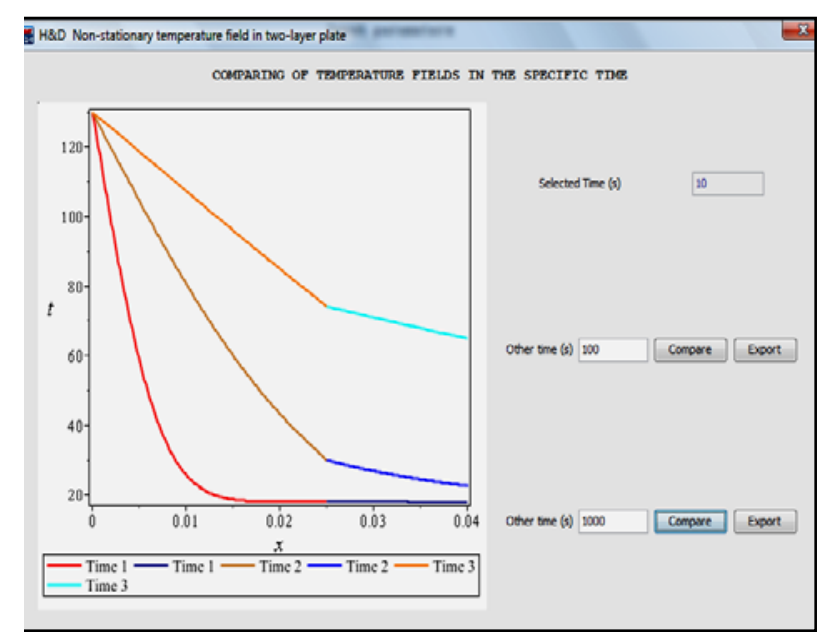

Fig. 3.Window for comparing of temperature fields

\section{CONCLUSION}

Based on analytical solution of mathematical model describing non-stationary heat transfer in the solid twolayer plate (Janáčová et al., 2011), we programmed application for study of heating or cooling course inside this body. Illustration of the relevant non-stationary heat conduction problems, speeding of computing of nonstationary heat conduction in a two-layer plate and visualization of temperature field in $2 \mathrm{D}$ and $3 \mathrm{D}$ projection are main benefits of the programmed application. Accuracy of our application enables it to be used for engineering computing in the processing industry.

\section{ACKNOWLEDGEMENTS}

This work was supported by the Ministry of Education, Youth and Sports of the Czech Republic under the Research Plan No. MSM 7088352102 and by the European Regional Development Fund under the project CEBIA-Tech No. CZ.1.05/2.1.00/03.0089.

\section{REFERENCES}

Abell, M. L. \& Braselton, J. B. (2005). Maple by example, Elsevier, ISBN 0-12-088526-3, London

Janáčová, D. et al. (2011). Temperature fields solving in twolayer plate with Comsol Multiphysics software, Proceedings of the 22nd DAAAM International World Symposium, 22-23th November 2011, Vienna, Katalinic, B. (Ed.), Published by DAAAM International, Vienna

Janáčová, D. et al. (2010). Modeling of non-stationary heat field in a plane plate for asymmetric problem, Proceedings of the 14th WSEAS International Conference on Systems. Latest Trends on Systems.Volume II, WSEAS Press (GR), Rhodes

Sýkorová, L.; Suba, O.; Malachová, M.; Černý, J. (2011) Temperature Field Simulation of Polymeric Materials During Laser Machining Using COSMOS / M Software , Proceedings of 13th WSEAS International Conference on Automatic control, modelling \& simulation (ACMOS'11), WSEAS Press, Lanzarote, Canary Islands

Vašek, L. \& Dolinay, V. (2010). Simulation Model of Heat Distribution and Consumption in Municipal Heating Network, Proceedings of 14th WSEAS International Conference on Systems. Latest Trends on Systems. Volume II, p.439-442, WSEAS Press (GR), Rhodes 